\title{
Still a long journey to decentralize geopolitics
}

\author{
Ning An \\ South China Normal University, China \\ Jo Sharp \\ University of St. Andrews, UK \\ Ian Shaw \\ University of Leeds, UK
}

\begin{abstract}
In this brief response paper, we respond to the insightful commentaries that critically engage with our original article in this forum. First, we discuss whether Confucian culture is fundamental to Chinese geo- politics, emphasizing how and why culture is part of a wider epistemic resource. We also note that our model is not normative, but an analytic framework for understanding complex non-western situations. Second, we discuss the geographies and scales of our model, noting a core tension between geopolitics at the state level and in everyday life. Third, we address the 'gap' between theory and practice under our Confucian model, noting that there is often a strategic inclusion (or exclusion) of Confucianism in practice. We finish by emphasizing that our paper is part a longer journey to further decentralize the western hold upon geopolitics.
\end{abstract}

\section{Keywords}

China, Confucianism, culture, geopolitics, practice, state

We would begin by thanking the commentators for their meticulous, insightful, and constructive comments on our paper. We value them as an opportunity and challenge to provide us with a space where we can continue discussions about the future possibilities (and limits) of a Confucian geopolitical model, the study of Chinese geopolitics, and a decentralized approach to world politics. At the outset, we want to reiterate the core point of view of our piece (An et al., 2021). Supported by many commentaries (Gonzalez-Vicente, 2021; Kong, 2021; Liu, 2021b), we insist that there was a form of geopolitics in ancient China, i.e. the Tian- xia (world-at-large) system established through the binary spatial imagination of Hua-Yi, and this was widely regarded as the philosophical foundation of world/state/national governance. However, this kind of geopolitics has gradually faded under the influences of western modernity, which illustrates the powerful effects of western 
modernity on other knowledges and worldviews (Mignolo, 2011). Meanwhile, the visibility of China and its growing influence on world politics is impossible to ignore. While the current Chinese government does not systematically use ancient ideas, in many respects, the historical traces of ancient thought (e.g. Confucianism) can still be seen to exist, whether at the discursive or practical level (discussed below). These contexts prove the necessity for thinking about what a Confucian geopolitical model might look like for understanding Chinese geopolitics and the influence of this state on world politics. On this basis, we believe being responsive to the existence of alternative geopolitical models should be an important direction of future geopolitical research. While doing so, we also agree with Gonzalez-Vicente's (2021) argument that we must be vigilant not to move from Western-centrism to a 'theoretical nationalism', 're-nationaliz[ing] instead of interna- tionaliz[ing]' knowledge production.

As we are restricted by space, we cannot reply to each of the commentator's points. Therefore, in this brief response, we aim to address three topics that most commentators touch upon. Thus, we first discuss whether Confucianism is fundamental to contemporary Chinese geopolitics. How this question is tackled ultimately requires us to con- sider the role of culture in world politics. Second, we address the geographies of Confucian geopolitics by examining the variegation of Confucian geopolitics through cases like Sinophone communities beyond mainland China. This discussion helps us to treat Confucian geopolitics as a decentralizing, denationalizing, and non-state-mandated rather than a renationalizing geopolitical model. Finally, we draw on the Confucian geopolitical model's 'slippage between narrative and practice' (Kong, 2021). In this part, we discuss what cases might convince us whether a Confucian geopolitics does matter for explanations of Chinese geo- politics (narrative and/or practice), and in the meanwhile, we also pay attention to how to tackle the changing relationship between narrative and practice.

\section{Is culture a fundamental approach to world politics?}

Turning to the first of the three outlined concerns, Weidong Liu, Ruben Gonzalez-Vicente, and Xin Liu all question our culturalist approach to Chinese geopolitics conferred to Confucianism that was anchored to our original piece on the topic. Liu (2021a) stresses that many concepts in modern Chinese culture and Confucianism are not the same (e.g. the concept of 'harmony' mentioned in our model), and suggests that we 'should avoid attributing everything to Confucian ideas and making Confucianism too fundamental to contemporary Chinese society and its geopolitics'. By referring to the Belt and Road Initiative (BRI) as an example, Liu (2021a: 3) advocates that it should not be regarded as a cultural project but rooted in the mate- rial connections. As he writes, 'economic 
sustain- ability in general must be the priority of Belt and Road construction', while 'taking the BRI as a Chinese cultural project may itself be a product of a particular cultural imagination'. GonzalezVicente (2021) takes this argument further, doubting 'the need to subsume the study of geopolitics in China to cultural analysis', as in his mind 'post-colonial nation-state logic', 'securitization concerns', and other 'commercial and nationalist rationales' seem to be more explanatory than a culturalist approach. Liu (2021b) goes further still, warning that a deep intervention within the concept of culture might result in its 'unmoved' impact upon history and politics.

We believe that it is a misrepresentation to suggest we are simply using Confucian culture to explain contemporary Chinese geopolitics. There are two points that need to be clarified here. The first is the definition of Confucianism. In the 'hybrid' model proposed by our article, we emphasize that 'Confucianism is inclusive of other geopolitical and geo-economic cultures, and the adaptability and openness of Confucian culture to other ways of thinking is an important component of hybrid Confucian geopolitical theory' (An et al., 2021). In other words, Confucianism in our model is not understood from the perspective of a fundamentalism in the narrow sense (that is, the emphasis on patriarchy, hierarchy, obedience, order, and harmony), but a generalization and hybridization of a continuation of broader traditional Chinese culture, which includes an eclectic coexistence of other cultures. Second, we do not intend to place traditional Chinese culture represented by Confucianism at the core position of understanding contemporary Chinese geopolitics. Here we very much agree with Gonzalez-Vicente (2021) who 'believe[s] it is necessary to de-centre official Confucian rhetoric in order to make space for the many contestations of state power that rely on different geopolitical imaginaries and cultural understandings of state-society relations', thus opposing any single factor as a decisive factor for Chinese geopolitics. As our article emphasizes, we are bringing Confucianisman aspect that has long been neglected by mainstream geopolitical studies-into a hybrid analytical frame- work of Chinese geopolitics, rather than placing it in a decisive position. This argument also echoes the title of this author response, which is to advocate for a decentralized geopolitical agenda. Gonzalez-Vicente (2021) and Liu (2021b) also warn of the trap of a culturalist approach in geopolitics. Paralleling our response to critiques of the role of Confucianism in explaining contemporary Chinese geopolitics, a culturalist approach may not be dominant in world politics, but neither can it be ignored. Modernity is not only an economic project, but also a cultural one, a process by which pre- existing social systems and ideologies are constantly being (re)shaped (Schmidt, 2006). In the last three decades, critical geopolitics has made the cultural embeddedness of geopolitical theory and practice very clear, whether the Manichean worldview of the Cold War or of the growing populist cultures of many 21st century leaders. So, here we insist that a culturalist approach is not a central explanatory variable but is nonetheless part of a hybrid analytical approach 
for future geopolitical analyses. More- over, in highlighting the existence of what we are calling a Confucian geopolitics, we are not advocating for it - this is not a normative agenda (such as critical or feminist geopolitics) but purely an identification of a different cultural genealogy behind the geographical imaginations inherent in any geo- political representation and practice. Rather than seeing Confucian geopolitics as a normative model, we would more like the readers to understand it as an analytical framework that help us make sense of complex non-western situations.

\section{Geographies of Confucian geopolitics}

The second criticism of our original piece comes from the question of whether a Confucian geopolitics is a statist geopolitical model. Gao et al. (2021) and Law (2021) point to the Sino-centric Chinese- ness and state-mandated Confucianism implied in our model and by doing so indicate the narrowness of our model as a way to explain modern Chinese geopolitics. Taking Singapore's Sinophone communities as examples, Gao et al. (2021) examine the crucial role of Confucian culture (e.g. kinship, guanxi, and ethnic intimacy) 'in shaping the eco- nomic and geopolitical landscape of both host countries and China'. More importantly, with this case, Gao et al. (2021) emphasize the concept of 'Confucian communitarianism' and advocate for a non-statist perspective to examine the variegated practices of Confucian geopolitics in a wider geo- graphical space. Compared with Gao et al.'s (2021) examination of the variegated practices of Confucian geopolitics at the spatial level, Law (2021) pays more attention to the variegated practices of Confucian geopolitics at the temporal level. Through a historical lens, Law (2021) believes that the hybridity of our Confucian geopolitics should also address the historical fate of Confucianism in modern China, especially in the Republican era (1911-1949) and in the early years of the People's Republic of China (PRC). On this basis, we can discuss the overseas spread of Confucianism (e.g. in Hong Kong, Macao, Taiwan, and East Asia), its diversified practices, and its retrospective influence on contemporary Chinese geopolitics. We appreciate the insights of Gao et al.'s (2021) and Law's (2021) engagement with our paper and feel their arguments will no doubt help to further develop and refine a Confucian geopolitical model. We will discuss two key points that emerge from their critiques. First, as they note, a discussion of the spatial-temporal distinctions in Confucianism would be very helpful to enrich our understanding of contemporary Chinese geopolitical practices as well as to theorize it. For example, it would be interesting to discuss how Confucianism mediates geo- politics in regions like Hong Kong, Taiwan, and many parts of Asia where there are variegated practices of Confucianism and also many hotspot geo- political issues. Second, we agree that we paid too little attention to the spectrum of Confucianism in our original piece, in which we only focus on how the state elites utilize Confucianism in theoretical and practical constructions of contemporary Chinese geopolitics. 
However, this does not mean that Confucian geopolitics is irrelevant to non-state scales. We fully agree with Gao et al.'s (2021) proposal to expand Confucian geopolitics to non-state scales, for instance to discuss the geopolitical architecture of Confucianism at individual, family, and community levels. This may greatly enhance the explanatory power of our Confucian geopolitical model in line with a distinctly feminist geopolitical approach that would regard these scales as inherently interconnected and interdependent (Dowler and Sharp, 2001). In fact, there are now tens of millions of ethnic Chinese outside of main- land China, who exist at a practical and imaginative distance from the state, and so may draw upon their own Confucian ideals (and unique interpretations and intimate relationships with Confucian- ism) to make sense of their own hybrid lives and communities.

We appreciate the commentators' warnings of the potential traps of state-centrism and Sino- centric geopolitics faced by our model. The meaningful dialogues with our respondents have helped us think through the tensions (and challenges of exceptionalism) inherent in our attempts to decentralize geopolitics through our attempts to map out a Confucian model.

\section{Practices of Confucian geopolitics}

While most commentators acknowledge our identification of Confucian philosophy's influence on modern Chinese geopolitics, they also express concern with how Confucian geopolitics is reflected in contemporary Chinese geopolitical practices, rather than in theories. This is a concern we share, and was the subject of debate among the three of us when writing our paper. The commentators' concern is mainly articulated in two ways. The first is about the empirical evidence of Confucian geopolitics, i.e. what kinds of cases could demonstrate that Chinese geopolitics is Confucian? Kong (2021), for example, questions how Confucian geopolitics could help us to understand hotly-debated Chinese geopolitical topics, such as the South China Sea, the Sino-US trade war, and the Taiwan issue, and on this basis urges for 'evidence-based empirical analyses of the myriad geopolitical tangles and geo-economic projects that China is mired in'. On the one hand, we agree that this would be an effective way to test the Confucian geopolitical model that is worthy of attention in future work. In fact, Bennett (2021) offers the case of Hong Kong, discussing the Confucian values in the Chinese central government's discourse and policy practices during the 2019 Hong Kong riots and the renovation of the West Kowloon Cultural District. An's (2019) previous work also demonstrates the role of Confucian philosophy in China's international security discourse. Both empirical cases lend support to our Confucian geo- political model. However, we also want to reiterate our argument for decentralizing geopolitics. As our approach lies within the critical 
geopolitical tradition of understanding the relationships between representation and practice, we can see that the mechanisms of many Chinese geopolitical issues are not always the same. The influence of Confucian philosophy as an epistemic framework is not necessarily consistent but is drawn upon strategically and in different contexts, just as it has been noted that narratives of the frontier and exceptionalism are judiciously drawn into US geopolitics on very specific occasions. So, we do not believe that all con- temporary Chinese geopolitical practices are reducible to Confucianist thought, but that Confucianism may at times serve as an epistemic and strategic resource for state and non-state practices and justifications.

Second, the commentators' concerns are also reflected in their worries over the slippages between narrative and practice in Confucian geopolitics. Kong (2021) re-emphasizes the convergence and divergence between Confucian geopolitical discourse and practice mentioned in our model, and invites us to elaborate on the divergences that might appear. In our discussion of the hybrid nature of the Confucian geopolitical model, we note that the current dynamics of Chinese geopolitics are multi- faceted, involving the coexistence between Confucian philosophy and other elements (An et al., 2021). This hybridity is what leads to an apparent gap between narrative and practice, because other forces, which are unpredictable, will be involved in the processes of implementation. So, it is important for us to treat Confucian geopolitical discourse, practice, and their divergences as well as their strategic convergence, dialectically.

Like Kong (2021), we regard this paper as an initial contribution to a much longer process of opening up the Western-centered discipline of geo- politics to a wider range of worldviews and epistemic scripts. Perhaps, inevitably, our model has oversimplified a complex cultural context, history, and geography, and so we appreciate the insight of the commentators' contributions to sharpening our thoughts.

\section{References}

An N (2019) Confucian values and Chinese geopolitical discourse on terrorism: China's reappraisal of international security politics. Eurasian Geography and Economics 60(3): 284-303.

An N, Sharp J and Shaw I (2021) Towards a Confucian geopolitics. Dialogues in Human Geography. DOI: 10. 1177/2043820620951354.

Bennett MM (2021) Aftershocks of empire: Hong Kong and the reordering of geopolitics. Dialogues in Human Geography. DOI: 10.1177/20438206211017740.

Dowler L and Sharp J (2001) A feminist geopolitics? Space and Polity 5(3): 165-176. 
Gao Q, Tse JKH and Woods O (2021) What and whose Confucianism? Sinophone communities and dialogical geopolitics. Dialogues in Human Geography. DOI: 10.1177/20438206211017768.

Gonzalez-Vicente R (2021) Why a critical geopolitics cannot be Confucian. Dialogues in Human Geography. DOI: 10.1177/20438206211017769.

Kong L (2021) A journey of a thousand miles begins with a single step: towards a Confucian geopolitics. Dialogues in Human Geography. DOI: 10.1177/ 20438206211017771.

Law AM (2021) Situating strategic or hybrid Confucian- ism(s): issues and problematics. Dialogues in Human Geography. DOI: 10.1177/20438206211017772.

Liu W (2021a) Confucian geopolitics or Chinese geopolitics? Dialogues in Human Geography. DOI: 10. $1177 / 20438206211017774$.

Liu X (2021b) Towards a Confucian geopolitics: a critical remark. Dialogues in Human Geography. DOI: $10.1177 / 20438206211017773$.

Mignolo WD (2011) The Darker Side of Western Modernity. Durham, NC: Duke University Press.

Schmidt VH (2006) Multiple modernities or varieties of modernity? Current Sociology 54(1): 77-97. 